\title{
Production of Struvite from Beverage Waste as Phosphorus Source
}

\author{
Edson Luiz Foletto ${ }^{\text {**, Wilson Roberto Barreto dos Santos }}$, \\ Marcio Antonio Mazutti, Sérgio Luiz, Jahn ${ }^{\mathrm{a}}$, André Gündel

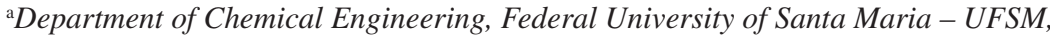 \\ CEP 97105-900, Santa Maria, RS, Brazil \\ ${ }^{\mathrm{b}}$ University Campus, Federal University of Pampa - UNIPAMPA, CEP 96413-170, Bagé, RS, Brazil \\ Received: December 5, 2011; Revised: September 19, 2012

\begin{abstract}
In this work was investigated the influence of $\mathrm{pH}$ on the synthesis of struvite using cola beverage waste as source of phosphorus. The process was operated in a batch reactor. The reaction time was 20 minutes, and the chemicals $\mathrm{MgCl}_{2} \cdot 6 \mathrm{H}_{2} \mathrm{O}$ and $\mathrm{NH}_{4} \mathrm{Cl}$ were used in the experiment, with a molar ratio of $\mathrm{Mg}^{+2}: \mathrm{NH}_{4}^{+}: \mathrm{PO}_{4}^{3-}=1: 1: 1$. The products were characterized by X-ray diffraction (XRD), atomic force microscopy (AFM), surface area (BET), thermogravimetric analysis (TGA) and infra-red (IR). From the results was verified the formation of a crystalline phase at $\mathrm{pH} 9.5$, with a surface area of $6.59 \mathrm{~m}^{2} \mathrm{~g}^{-1}$ and a particle size of about $0.25 \mu \mathrm{m}$
\end{abstract}

Keywords: struvite, characterization, beverage waste, phosphorous

\section{Introduction}

Struvite $\left(\mathrm{MgNH}_{4} \mathrm{PO}_{4} \cdot 6 \mathrm{H}_{2} \mathrm{O}\right)$ is a crystalline solid with equal molar concentrations of magnesium, ammonium and phosphorus and it has been used as slow-release fertilizer ${ }^{1}$ and as reagent for the preparation of magnesium phosphate cement materials ${ }^{2,3}$. The struvite precipitation process is an attractive method because it can remove and recover simultaneously $\mathrm{P}$ and $\mathrm{N}$ from wastewater ${ }^{4}$, decreasing the environmental impact as the eutrophication ${ }^{5}$. Different sources of phosphorus and nitrogen have been used for struvite production such as swine wastewater ${ }^{6}$, leather tanning wastewater ${ }^{7}$, waste sludge ${ }^{8}$, poultry wastewater ${ }^{9}$, municipal landfill leachate ${ }^{10}$ and synthetic form ${ }^{11}$. The formation of struvite normally occurs in alkaline medium, and the optimal $\mathrm{pH}$ value for struvite crystallization is reported in the range 8.0-11.0 $0^{(12,13)}$. Magnesium chloride $\left(\mathrm{MgCl}_{2}\right)$ has been widely used as a $\mathrm{Mg}$ source because of it quick dissociative nature, resulting in short reaction time ${ }^{14,15}$.

Although several works are reporting the use of different sources of phosphorous to synthesize the struvite, there are no studies concerning the evaluation of waste from the cola beverage as phosphorous source, since this beverage present high content of phosphorous ${ }^{16,17}$. In this sense, the main objective of this work was to investigate the influence of $\mathrm{pH}$ on the characteristics of struvite particles obtained by precipitation using cola beverage waste as phosphorous source. The materials were characterized by X-ray diffraction (XRD), atomic force microscopy (AFM), surface area (BET), thermogravimetric analysis (TGA) and infra-red (IR).

*e-mail: efoletto@gmail.com

\section{Experimental}

The sample used in this work was a cola beverage with shelf life expired obtained from a local beverage industry. The sample was maintained at $4{ }^{\circ} \mathrm{C}$ until the analysis. The experimental system consisted of a simple glass batch reactor $(11 \times 11 \times 17 \mathrm{~cm})$ with a total volume of $2.0 \mathrm{~L}$. The agitation of the reaction media was carried out using a paddle with diameter of $7.5 \mathrm{~cm}$ and height of $2.5 \mathrm{~cm}$. The working volume of the reactor was $1.0 \mathrm{~L}$, which was operated at $20{ }^{\circ} \mathrm{C}$ under agitation of $200 \mathrm{rpm}$. Analytical grade chemicals $\left(\mathrm{MgCl}_{2} \cdot 6 \mathrm{H}_{2} \mathrm{O}, \mathrm{NH}_{4} \mathrm{Cl}\right.$ and $\left.\mathrm{NaOH}\right)$ were used as received. In order to eliminate carbon dioxide dissolved in the beverage sample, a vigorous mechanical stirring was carried out by 5 hours before the experiments. The amounts of $\mathrm{MgCl}_{2} \cdot 6 \mathrm{H}_{2} \mathrm{O}$ and $\mathrm{NH}_{4} \mathrm{Cl}$ used in the tests were calculated according to the concentration of $\mathrm{PO}_{4}^{3-}$ present in the sample of beverage, considering a molar ratio of $1: 1: 1\left(\mathrm{Mg}^{+2}: \mathrm{NH}_{4}^{+}: \mathrm{PO}_{4}^{3-}\right)$. In this work, the concentration of total $\mathrm{PO}_{4}^{3-}$ was determined by ascorbic acid colorimetric method $^{18}$. The solution was prepared by dissolving amounts of cola beverage, magnesium chloride (1M) and ammonium chloride (1M), respectively, in the batch reactor. Afterwards, the $\mathrm{pH}$ of solution was adjusted to the desirable value (8.5, 9.0 and 9.5 ) by adding a $4 \mathrm{M} \mathrm{NaOH}$ solution. All the reaction runs were carried out during 20 minutes. The suspension was centrifuged, and the precipitate was washed with distilled water and dried at $50{ }^{\circ} \mathrm{C}$ for 6 hours

Nanopowder was characterized by X-ray diffractometry (XRD) (equipment Bruker D8 Advance, with $\mathrm{Cu} \mathrm{K} \alpha$ radiation). The average nanocrystallite size was determined through X-ray diffraction (and reflection) line broadening using the Scherrer equation ${ }^{19}: D=K . \lambda /(\beta \cdot \cos \theta)$, where $D$ is the crystallite size, $\mathrm{K}$ is the Scherrer constant (0.90), $\lambda$ is 
the wavelength of the X-ray radiation $(0.1542495 \mathrm{~nm}$ for $\mathrm{Cu}-\mathrm{K} \alpha$ ), and $\beta$ is the peak width at half height and finally $\theta$ corresponds to the peak position (in the current study, $2 \theta=20.84)$. The morphology of particles was examined by atomic force microscopy (Agilent Technologies 5500 equipment). Thermogravimetric analysis (TGA) was carried out on Q500 analyzer (TA instruments) using a heating rate of $10{ }^{\circ} \mathrm{C} / \mathrm{min}^{-1}$ at an air flow rate of $50 \mathrm{~mL} / \mathrm{min}^{-1}$. The BET surface area was obtained from nitrogen adsorption isotherms at $77 \mathrm{~K}$, conducted on an ASAP 2020 system, at a relative pressure (P/Po) from 0 to 0.99. ). IR spectra were recorded on a PerkinElmer FT-IR Spectrum spectrophotometer in the region of $600-3900 \mathrm{~cm}^{-1}$, using $\mathrm{KBr}$ pellets.

\section{Results and Discussion}

The concentration of phosphorus in the cola beverage sample was $415 \mathrm{mg} \mathrm{PO}_{4}{ }^{3-} \mathrm{L}^{-1}$, decreasing its value to $12 \mathrm{mg} \mathrm{PO}_{4}{ }^{3-} \mathrm{L}^{-1}$ after the struvite production for all experimental conditions, implying in a reduction of $97 \%$ of the initial phosphorus content. Removal of phosphorus ranging from 55 to $98 \%$ in different experimental conditions has been reported using liquid swine manure ${ }^{20}$. Recovery efficiency of phosphorus between 80 and $90 \%$ was achieved in the treatment of sludge digester liquors ${ }^{21}$.

The analysis of XRD was used to characterize the synthesized powders (Figure 1). It was verified the formation of amorphous solids at runs carried out at $\mathrm{pH} 8.5$ and 9.0 (Figure 1a). However, at pH 9.5 (Figure 1a), was verified the formation of crystalline struvite. The formation of struvite was indicated by location of the peaks, corresponding to reference database lines for struvite (Figure 1b). By applying of Scherrer equation, the average nanocrystallite size was about $55 \mathrm{~nm}$. Several authors have been reported that the formation of crystalline struvite is verified in a narrow range of $\mathrm{pH}$, which is closely related to the raw material characteristics. By example, for struvite precipitation using swine wastewater as raw material, different values of $\mathrm{pH}$ such as $8.0-8.5^{(22)}, 8.5^{(23)}, 9.0^{(8)}, 8.9-9.25^{(24)}, 9.5-10.5^{(25)}$ were reported. The narrow range of $\mathrm{pH}$ for synthesis of crystalline struvite is because maintaining the $\mathrm{pH}$ above the optimum point occurs the formation of $\mathrm{Mg}_{3}\left(\mathrm{PO}_{4}\right)_{2}$ instead of struvite, whereas at $\mathrm{pH}$ below the optimum range promotes the increase of $\mathrm{H}^{+}$in the solution inhibiting the struvite crystallization $^{22}$.

The identification of struvite phase obtained at $\mathrm{pH}=9.5$ was confirmed by thermogravimetric analysis (TGA) (Figure 2a). According to the chemical structure of struvite $\left(\mathrm{MgNH}_{4} \mathrm{PO}_{4} \cdot 6 \mathrm{H}_{2} \mathrm{O}\right)$, the theoretical mass loss under heating should be $51.42 \%$, due to mass losses of water $(44.08 \%)$ and ammonium $(7.34 \%)$. From Figure $2 \mathrm{a}$ it is seen that the mass loss was about $50 \%$, that is very close to the theoretical $(51.42 \%)$ and similar to those reported by other researchers $(51 \% \text { and } 52.49 \%)^{11,26}$. AFM image (Figure 2b) indicated that the struvite particles obtained at $\mathrm{pH}=9.5$ presented quasi-spherical shape with size of about $0.25 \mu \mathrm{m}$, which are formed by agglomeration of nanocrystals.

The $\mathrm{N}_{2}$ adsorption-desorption curves were of type IV with H3-type hysteresis loop (in accordance with IUPAC classification $)^{27}$ at relative pressure $>$ ca. 0.3 , as shown in Figure 3 . The shape of the isotherms suggested that the sample obtained at $\mathrm{pH}=9.5$ presented basically mesoporous structure. It was confirmed by analysis of pore size distribution (see insert in Figure 3), which was unimodal, and showed spectra of pore diameter in the mesopous region, according to the IUPAC classification ${ }^{27}$. Therefore, struvite had mesopores, most likely due to the interparticles and out-of-order porosity. The results of surface area and total pore specific volume (at $\mathrm{P} / \mathrm{Po}=0.99$ ) were $6.59 \mathrm{~m}^{2} \cdot \mathrm{g}^{-1}$ and $0.0254 \mathrm{~cm}^{3} \cdot \mathrm{g}^{-1}$, respectively.

The identification of single-phase struvite obtained at $\mathrm{pH}=9.5$ was also confirmed by IR spectroscopy (Figure 4). The band at $2970 \mathrm{~cm}^{-1}$ was the antisymmetric stretching vibration of $\mathrm{NH}_{4}$ groups. The broad band between 2500 and $2200 \mathrm{~cm}^{-1}$ was assigned to water-phosphate $\mathrm{H}$ bonding. $\mathrm{HOH}$ deformation of water was at $1680 \mathrm{~cm}^{-1}$, and the bands

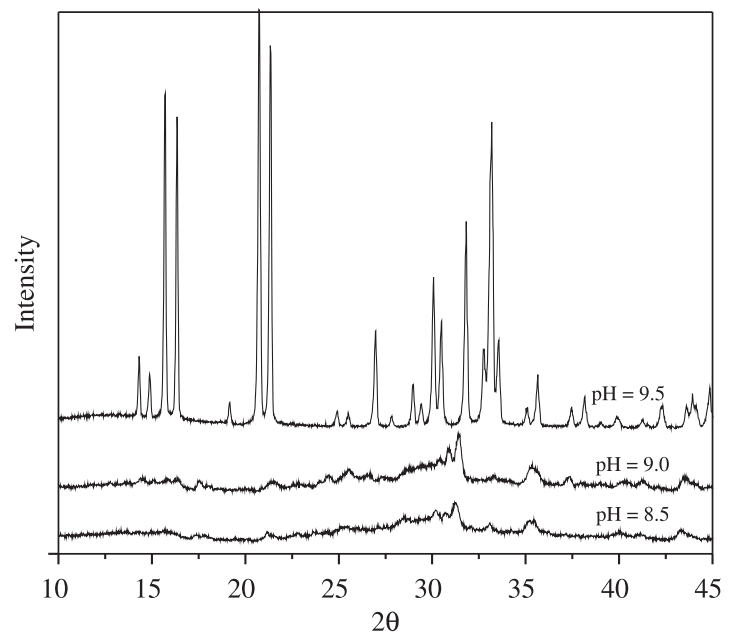

(a)

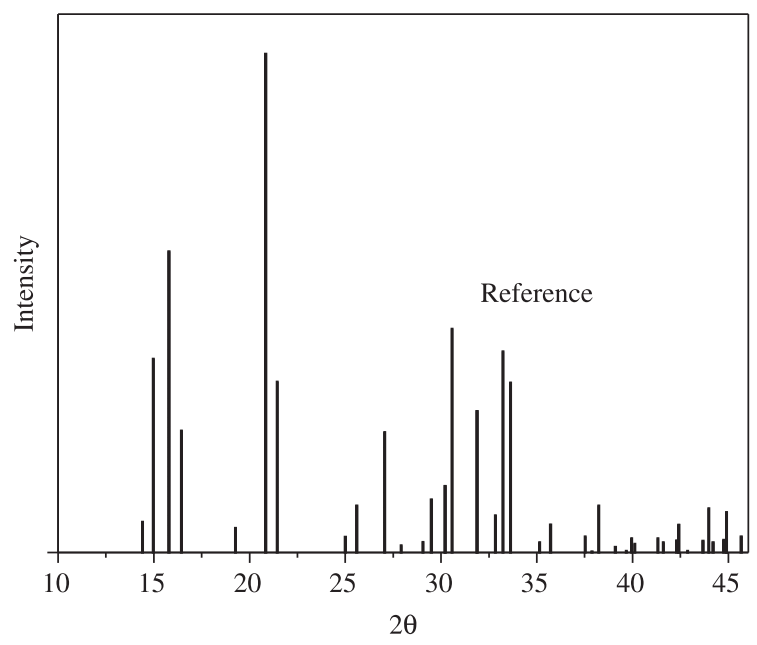

(a)

Figure 1. XRD analysis of (a) samples obtained at different pH values, and (b) reference struvite (JCPDS Card No 1-077-2303). 


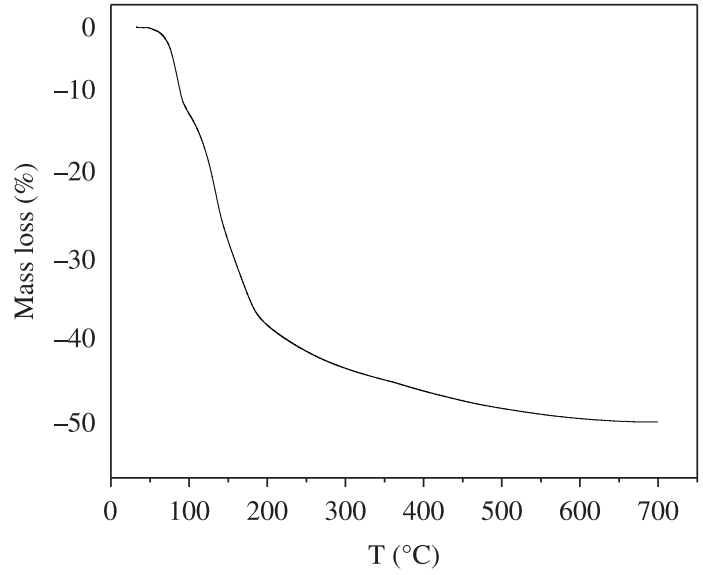

(a)

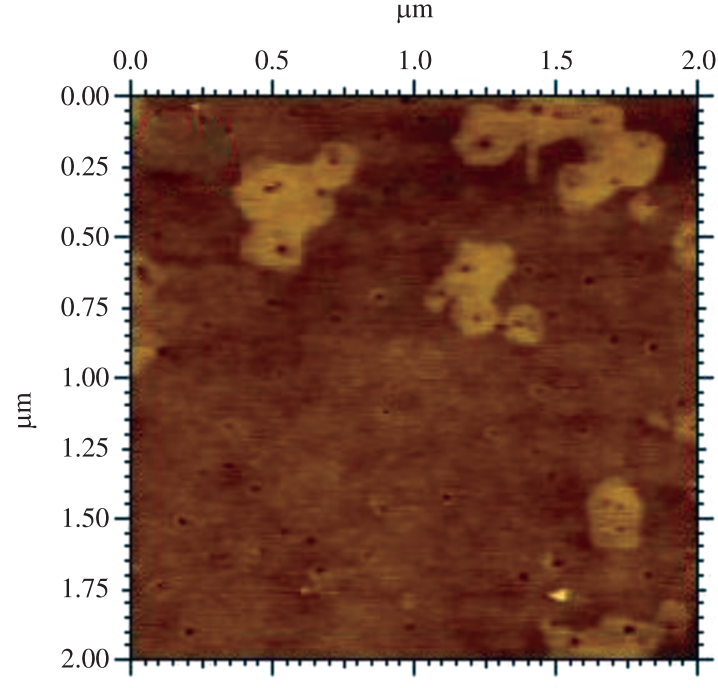

(b)

Figure 2. (a) TGA pattern and (b) AFM image of struvite sample obtained at $\mathrm{pH} 9.5$.

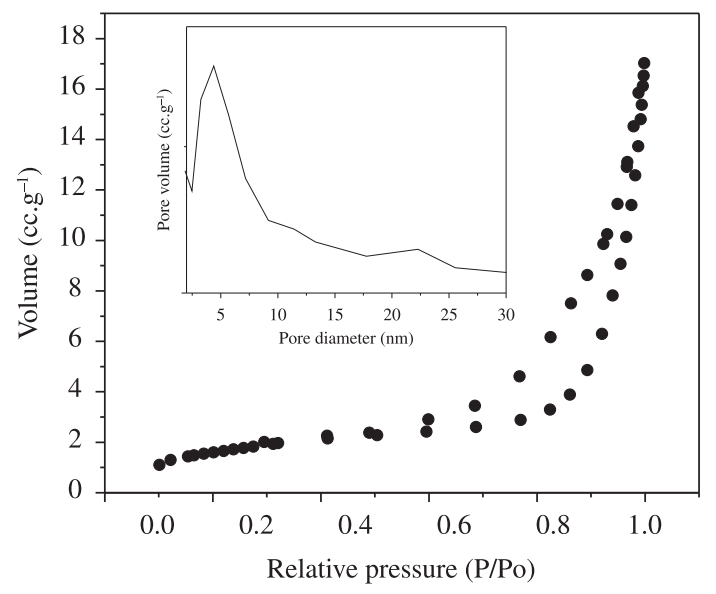

Figure 3. $\mathrm{N}_{2}$ ad/desorption isotherms and pore size distribution of struvite sample obtained at $\mathrm{pH} 9.5$.

seen over the range of 1600 to $1400 \mathrm{~cm}^{-1}$ were those of the $\mathrm{HNH}$ deformation modes of $\mathrm{HN}_{4}$. The band of $\mathrm{PO}_{4}$ unit was observed at $1006 \mathrm{~cm}^{-1(28)}$. Water-water $\mathrm{H}$ bonding were observed at 760 and $695 \mathrm{~cm}^{-1}$, whereas ammonium-water $\mathrm{H}$ bonding was observed at $890 \mathrm{~cm}^{-1(28)}$.

\section{Conclusions}

This study investigated the phosphorus removal and recovery from cola beverage waste by struvite crystallization process. From the results was verified that $\mathrm{pH}$ influenced the

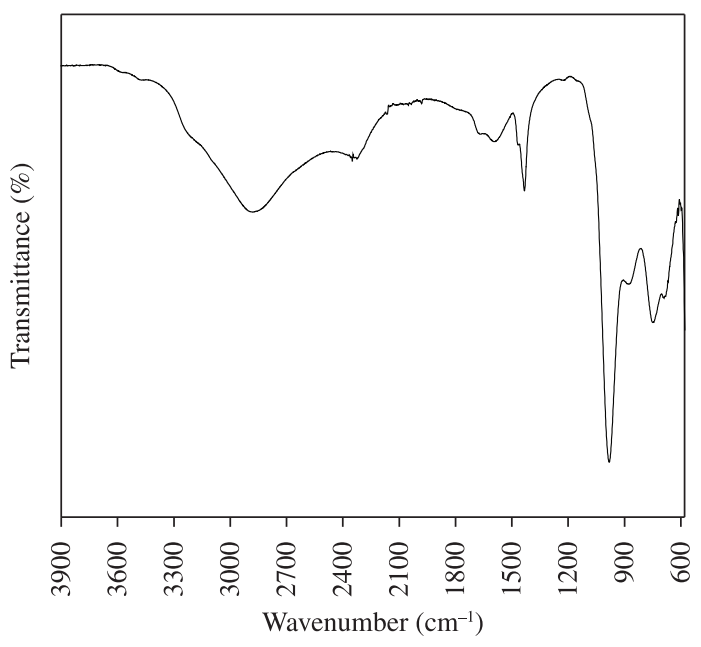

Figure 4. IR data of struvite sample obtained at $\mathrm{pH} 9.5$.

crystalline struvite precipitation, where the $\mathrm{pH} 9.5$ showed to be the most suitable for the synthesis. The recovered solids at $\mathrm{pH} 9.5$ presented a pure and crystalline phase, with a particle size in the micrometric scale. Thus, the struvite can be produced from waste of cola beverage industries.

\section{Acknowledgements}

The authors are grateful to the Brazilian research funding, $\mathrm{CNPq}$, for the financial support. 


\section{References}

1. Bridger GL, Salutsky ML and Starostka RW. Metal ammonium phosphates as fertilizers. Journal of Agricultural and Food Chemistry. 1962;10:181-188. http://dx.doi.org/10.1021/ jf60121a006

2. Ribeiro DV and Morelli MR. Performance analysis of magnesium phosphate cement mortar containing grinding dust. Materials Research. 2009;12(1):51-56. http://dx.doi. org/10.1590/S1516-14392009000100005

3. Ribeiro DV and Morelli MR. Influence of the addition of grinding dust to a magnesium phosphate cement matrix. Construction and Building Materials. 2009;23:3094-3102. http://dx.doi.org/10.1016/j.conbuildmat.2009.03.013

4. Liu Y, Kwag J, Kim J and Ra C. Recovery of nitrogen and phosphorus by struvite crystallization from swine wastewater. Desalination. 2011;277:364-369. http://dx.doi.org/10.1016/j. desal.2011.04.056

5. Haddrill V, Keffer R, Olivetti GC, Polleri GB and Giovanardi F. Eutrophication problems in Emilia Romagna, Italy: Monitoring the nutrient load discharged to the littoral zone of the Adriatic Sea. Water Research. 1983;17:483-495. http:// dx.doi.org/10.1016/0043-1354(83)90108-2

6. Song Y, Qiu G, Yuan P, Cui X, Peng J, Zeng P et al. Nutrients removal and recovery from anaerobically digested swine wastewater by struvite crystallization without chemical additions. Journal of Hazardous Materials. 2011;190:140-149. http://dx.doi.org/10.1016/j.jhazmat.2011.03.015

7. Tünay O, Kabdasli I, Orhon D and Kolçak S. Ammonia removal by magnesium ammonium phosphate precipitation in industrial wastewaters. Water Science and Technology. 1997;36:225-228. http://dx.doi.org/10.1016/S0273-1223(97)00391-0

8. Jaffer Y, Clark TA, Pearce P and Parsons SA. Potential phosphorus recovery by struvite formation. Water Research. 2002;36:1834-1842. http://dx.doi.org/10.1016/ S0043-1354(01)00391-8

9. Yetilmezsoy K and Sapci-Zengin Z. Recovery of ammonium nitrogen from the effluent of UASB treating poultry manure wastewater by MAP precipitation as a slow release fertilizer. Journal of Hazardous Materials. 2009;166:260-269. http:// dx.doi.org/10.1016/j.jhazmat.2008.11.025

10. Kim D, Ryu H, Kim M, Kim J and Lee S. Enhancing struvite precipitation potential for ammonia nitrogen removal in municipal landfill leachate. Journal of Hazardous Materials. 2007;146:81-85. http://dx.doi.org/10.1016/j. jhazmat.2006.11.054

11. Wang C, Hao X, Guo G and Van Loosdrecht MCM. Formation of pure struvite at neutral $\mathrm{pH}$ by electrochemical deposition. Chemical Engineering Journal. 2010;159:280-283. http:// dx.doi.org/10.1016/j.cej.2010.02.026

12. Laridi R, Auclair J and Benmoussa H. Laboratory and pilot-scale phosphate and ammonium removal by controlled struvite precipitation following coagulation and flocculation of swine wastewater. Environmental Technology. 2005;26:525-536. http://dx.doi.org/10.1080/09593332608618533

13. Hanhoun M, Montastruc L, Azzaro-Pantel C, Biscans B, Frèche $\mathrm{M}$ and Pibouleau L. Temperature impact assessment on struvite solubility product: A thermodynamic modeling approach. Biochemical Engineering Journal. 2011;167:50-58. http://dx.doi.org/10.1016/j.cej.2010.12.001

14. Li XZ and Zhao QL. Recovery of ammonium-nitrogen from landfill leachate as a multi-nutrient fertilizer. Ecological
Engineering. 2003;20:171-181. http://dx.doi.org/10.1016/ S0925-8574(03)00012-0

15. Liu Z, Zhao Q, Lee DJ and Yang N. Enhancing phosphorus recovery by a new internal recycle seeding MAP reactor. Bioresource Technology. 2008;99:6488-6493. http://dx.doi. org/10.1016/j.biortech.2007.11.039

16. Forsberg C. The large-scale flux of nutrients from land to water and the eutrophication of lakes and marine waters. Marine Pollution Bulletin. 1994;29:409-413. http://dx.doi. org/10.1016/0025-326X(94)90663-7

17. Karp H, Ekholm P, Kemi V, Itkonen S, Hirvonen T, Närkki $S$ et al. Differences among total and in vitro digestible phosphorus content of plant foods and beverages. Journal of Renal Nutrition. 2012; 22(4):416-22.

18. Perera PW A, Wu WX, Chen YX and Han ZY. Struvite Recovery from Swine Waste Biogas Digester Effluent through a Stainless Steel Device under Constant pH Conditions. Biomedical and Environmental Sciences. 2009;22:201-209. http://dx.doi.org/10.1016/S0895-3988(09)60046-5

19. Moore DM and Reynolds Junior RC. X-ray diffraction and the identification and analysis of clay minerals. Oxford University Press, Inc.; 1989.

20. Çelen I, Buchanan J, Burns R, Robinson R and Raman D Using a chemical equilibrium model to predict amendments required to precipitate phosphorus as struvite in liquid swine manure. Water Research. 2007;41:1689-1696. http://dx.doi. org/10.1016/j.watres.2007.01.018

21. Martí N, Pastor L, Bouzas A, Ferrer J and Seco A. Phosphorus recovery by struvite crystallization in WWTPs: Influence of the sludge treatment line operation. Water Research. 2010;44:2371-2379. http://dx.doi.org/10.1016/j. watres.2009.12.043

22. Huang $\mathrm{H}, \mathrm{Xu} \mathrm{C}$ and Zhang $\mathrm{W}$. Removal of nutrients from piggery wastewater using struvite precipitation and pyrogenation technology. Bioresource Technology. 2011;102:2523-2528. http://dx.doi.org/10.1016/j.biortech.2010.11.054

23. Suzuki K, Tanaka Y, Osada T and Waki M. Removal of phosphate, magnesium and calcium from swine wastewater through crystallization enhanced by aeration. Water Research. 2002;36:2991-2998. http://dx.doi.org/10.1016/ S0043-1354(01)00536-X

24. Nelson NO, Mikkelsen RL and Hesterberg DL. Struvite precipitation in anaerobic swine lagoon liquid: effect of $\mathrm{pH}$ and $\mathrm{Mg}: \mathrm{P}$ ratio and determination of rate constant. Bioresource Technology. 2003;9:229-236. http://dx.doi.org/10.1016/S09608524(03)00076-2

25. Song Y, Yuan P, Zheng B, Peng J, Yuan F and Gao Y. Nutrients removal and recovery by crystallization of magnesium ammonium phosphate from synthetic swine wastewater. Chemosphere. 2007;69:319-324. http://dx.doi.org/10.1016/j. chemosphere.2007.06.001

26. Bhuiyan MIH, Mavinic DS and Koch FA. Thermal decomposition of struvite and its phase transition. Chemosphere. 2008;70:1347-1356. http://dx.doi.org/10.1016/j. chemosphere.2007.09.056

27. International Union of Pure and Applied Chemistry - IUPAC. Manual of Symbols and Terminology. Pure and Applied Chemistry. 1972; 31:578.

28. Kurtulus G and Tas AC. Transformations of neat and heated struvite $\left(\mathrm{MgNH}_{4} \mathrm{PO}_{4} \cdot 6 \mathrm{H}_{2} \mathrm{O}\right)$. Materials Letters. 2011;65:28832886. http://dx.doi.org/10.1016/j.matlet.2011.06.086 